\title{
Limb trauma: the use of an advanced wound care device in the treatment of full-thickness wounds
}

\author{
L. Vaienti - A. Marchesi - G. Palitta • \\ R. Gazzola $\cdot$ P. C. Parodi $\cdot$ F. Leone
}

Received: 9 November 2012/ Accepted: 15 July 2013/Published online: 30 July 2013

(C) The Author(s) 2013. This article is published with open access at Springerlink.com

\begin{abstract}
This is an observational case series of 15 patients with full-thickness traumatic wound defects treated with a dermal substitute. There were 8 male and 7 female patients with a mean age of 36.6 years. Eight patients had trauma to the lower limbs and 7 were of the upper limbs, with the average lesion size $104.4 \mathrm{~cm}^{2}$ (range 6-490 $\mathrm{cm}^{2}$ ). The time to complete healing had a mean average time of 26.8 days (range 16-60 days). All patients went on to successful repair with 6 patients requiring a second application of the substitute and 5 patients needing split thickness skin grafts. Infection was recorded in one patient.
\end{abstract}

Keywords Upper limb - Lower limb - Hyaluronic acid $\cdot$ Full-thickness wound

\section{Introduction}

In the last few decades, there has been a search for solutions in tissue repair without need for autografts. This has produced a development of biological substitutes that could repair or improve the function of tissue. The use of these products enlarges the spectrum of therapeutic resources available for the treatment of skin lesions, thereby changing the approach to many diseases [1]. The advent of

L. Vaienti $(\bowtie) \cdot$ A. Marchesi · G. Palitta · R. Gazzola •

F. Leone

Department of Plastic Surgery, IRCCS Policlinico San Donato,

San Donato Milanese, MI, Italy

e-mail: francescobrsb@hotmail.it

P. C. Parodi

O.U. of Plastic Surgery, Ospedale della Misericordia,

Udine, UD, Italy so-called advanced wound care dressings has revolutionized the treatment of soft tissue loss, especially in burns and difficult wounds, e.g., pressure and vascular diabetic ulcers, to become an essential resource.

Derivatives of hyaluronic acid (HA) are of particular importance within the field of dermal replacement products [2-7]. HA is the main degradation product in these substitutes and exerts many effects on wound healing, including maintenance of the homeostasis [8], enhancement of the angiogenesis [9] and organization of collagen deposition [10]. HA benefits epithelial regeneration also, and the HA macromolecule seems to have free-radical scavenging properties. HA derivatives are available in several esterified forms, one of which is $\mathrm{HYAFF}^{\circledR}$ (benzyl esters of hyaluronic acid), a biopolymer organized in a three-dimensional scaffold that allows fibroblast colonization producing an ordered reconstruction of dermal tissue [11]. One of these recent HA derivatives is a dermal substitute composed by HYAFF, used in burn care practice as biological regenerative matrix on both deep partial-thickness and full-thickness burns and as temporary coverage of the wounds [1, 12]. We have looked at the efficacy of this substitute, originally developed for dermal regeneration in different full-thickness wounds, for cases of limb trauma with exposed bone or tendon which continue to be challenging problems for plastic surgeons. We have undertaken this observational study to evaluate the clinical efficacy and safety of the product on dermal regeneration in cases of severe soft tissue loss.

\section{Materials and methods}

This prospective case series included 15 patients with fullthickness wounds caused by trauma which were treated 
with the dermal substitute; the series was accrued from June 2007 to May 2010. All patients were informed about product use and consented to the study. There were 8 male and 7 female patients with a mean age of 36.6 years. Eight patients had trauma to the lower limbs and 7 were of the upper limbs, with the average lesion size $104.4 \mathrm{~cm}^{2}$ (range 6-490 $\mathrm{cm}^{2}$ ), (Table 1). Twelve patients had exposed tendons and two had exposed bone (no area of bone exposure exceeded $2 \mathrm{~cm}^{2}$ ). The causes of trauma were, in ten cases $(66 \%)$, accidents at work or home; in three cases (20\%), burns and in two cases $(13.3 \%)$, surgical wounds. All cases were treated urgently, and none of the patients was affected by comorbidities. Evaluation of inflammatory indexes (white cells, CRP and ESR) were carried out at 3, 6, 10 days and 4 weeks after the application of the product. The assessment of clinical epithelialization and the aesthetic quality of the newly formed skin (skin texture, color similarity and elasticity) were performed at least 6 weeks after product application. In six patients (40\%), a second application was necessary. The layer was left on the wounds for a mean time of 15.9 days (range 14-21). Any adverse events and complications were recorded.

\section{Product application procedure}

Hyalomatrix ${ }^{\circledR} \mathrm{PA}$ is designed as a sterile, bi-layered wound dressing. It is a biodegradable, absorbent, non-woven pad entirely composed of HYAFF $^{\circledR}$ which constitutes the wound contact layer. The $\mathrm{HYAFF}^{\circledR}$ layer is physically coupled with a transparent and flexible film of a medicalgrade synthetic elastomer that acts as a semipermeable barrier against external contaminants. As the product is applied on the wound bed, the $\mathrm{HYAFF}^{\circledR}$ wound contact layer provides a three-dimensional scaffold that permits the colonization of the product by fibroblasts and onto which extracellular matrix components are laid down, resulting in an almost ordered reconstruction of the dermal tissue. The transparent elastomeric film, characterized by a vapor transmission rate comparable to that of normal skin, prevents excessive body fluid loss. The product conforms well to wound edges and can be cut to suit the shape of the lesion.

All wounds were subjected to a presurgical debridement and assessment of the lesion. Hemostasis of the visible bleeding points was carried out. Once a clean wound bed was obtained, an adequate-sized pad was shaped to the wound and applied with the $\mathrm{HYAFF}^{\circledR}$ scaffold in direct contact with the wound bed and contoured to the edges, sutured with nylon sutures and dressed with sterile cotton gauze. An elastic bandage was applied for a non-compressing cover. After a period of not less than 15 days, a complete inspection and assessment of the wound was performed by removing the silicon film. Depending on the achievement of the desired level of granulation tissue, it was decided if a new application of the product was necessary. If a wound bed with a good blood supply was observed, repeated washing with saline was carried out and dressing with paraffin gauze followed by cotton gauze and a bandage applied. Patients returned for a change of dressings weekly. Swabs were taken for bacteriologic culture before application and thereafter at weekly intervals during wound inspection. Antibiotic prophylaxis (Cefazolin) was administered from the day of the product application for 3 days until microbiological results were

Table 1 Demography and baseline characteristics

\begin{tabular}{|c|c|c|c|c|c|c|c|c|c|}
\hline $\mathrm{N}^{\circ}$ & $\begin{array}{l}\text { Age } \\
\text { (years) }\end{array}$ & Sex & $\begin{array}{l}\text { Trauma } \\
\text { localization }\end{array}$ & Cause & $\begin{array}{l}\text { Lesion area } \\
\left(\mathrm{cm}^{2}\right)\end{array}$ & $\begin{array}{l}\text { Bone } \\
\text { exposure }\end{array}$ & $\begin{array}{l}\text { Tendon } \\
\text { lesion }\end{array}$ & $\begin{array}{l}\text { Hyalomatrix }{ }^{\circledR} \\
\text { PA }(n)\end{array}$ & $\begin{array}{l}\text { Hyalomatrix }{ }^{\circledR} \mathrm{PA} \\
\text { residence time (days) }\end{array}$ \\
\hline 1 & 45 & $\mathrm{~F}$ & Leg, third distal & Accident & $20 \times 8(160)$ & $+(2 \times 1 \mathrm{~cm})$ & + & 2 & $21+21$ \\
\hline 2 & 33 & M & Hand & Work accident & $16 \times 6(96)$ & - & + & 1 & 14 \\
\hline 3 & 17 & M & Hand & Surgery & $3 \times 6(18)$ & - & + & 1 & 14 \\
\hline 4 & 19 & M & Forearm & Work accident & $4 \times 8(32)$ & - & + & 1 & 14 \\
\hline 5 & 62 & M & Leg, third distal & Accident & $13 \times 9(117)$ & - & + & 2 & $21+21$ \\
\hline 6 & 42 & $\mathrm{~F}$ & Hand & Home accident & $6 \times 4(24)$ & - & + & 1 & 14 \\
\hline 7 & 34 & $\mathrm{~F}$ & Foot & Accident & $3 \times 4(12)$ & - & + & 1 & 14 \\
\hline 8 & 29 & $\mathrm{~F}$ & Foot & Accident & $6 \times 7(42)$ & - & + & 1 & 14 \\
\hline 9 & 3 & M & Hand & Burn & $5 \times 5(25)$ & - & - & 2 & $14+14$ \\
\hline 10 & 48 & M & Foot & Work accident & $12 \times 4(48)$ & - & + & 2 & $14+14$ \\
\hline 11 & 47 & $\mathrm{~F}$ & Hand & Burn & $3 \times 2(6)$ & - & - & 1 & 14 \\
\hline 12 & 51 & M & Leg, third distal & Surgery & $35 \times 14(490)$ & $+(2 \times 1 \mathrm{~cm})$ & + & 2 & $21+21$ \\
\hline 13 & 68 & $\mathrm{~F}$ & Thigh & Burn & $20 \times 16(320)$ & - & - & 2 & $14+14$ \\
\hline 14 & 22 & $\mathrm{~F}$ & Leg, third distal & Accident & $9 \times 4(36)$ & - & + & 1 & 14 \\
\hline 15 & 30 & M & Forearm & Work accident & $20 \times 7(140)$ & - & + & 1 & 14 \\
\hline
\end{tabular}

${ }^{\mathrm{a}}$ Lesion area by maximum length and width 
available. Each patient with clinical evidence of infection received appropriate antibiotic therapy (based on results of cultures), and dressing changes were increased to twice per week until the infection settled. Weekly dressing changes continued until epithelial healing was complete. Regular photographic documentation was taken before, during and after treatment.

\section{Results}

All treated cases $(n=15)$ had satisfactory tissue repair (Table 2). Out of 15 cases, 6 (40\%) needed a second application of the product in order to obtain the desired wound bed. Of the six, 3 had lesion sizes ranging from 117 to $390 \mathrm{~cm}^{2}$ needing autologous skin grafts to complete wound cover. Ten lesions (67\%) closed spontaneously by re-epithelialization (Fig. 1), but 5 cases (33\%) needed autologous skin grafts to complete the epithelialization process (Fig. 2). The time to complete healing had a mean average time of 26.8 days (range 16-60 days). The inflammatory indexes were normal in 13 cases $(87 \%)$ while in two cases $(13 \%)$ were positive. The assessment of the quality of the new skin was optimal for 5 cases $(33.3 \%)$, good in $7(46.6 \%)$ and modest in $3(20 \%)$. In one case $(6.7 \%)$, the onset of infection was observed, and this event delayed the epithelialization process; in this case, the second application of the product was postponed until a decrease in the inflammatory markers. No other complications were noticed during the product application and duration of the study.

\section{Discussion}

Limb injuries creating exposed bone or tendon continue to be challenging problems for plastic surgeons. There is now a better understanding of vascular anatomy of the lower leg and better use of improved wound care technology which has led to judicial use of flaps and delayed closures. Severe limb trauma has significant socio-economic effects; there is considerable expenditure in terms of direct costs (orthopedic implants and devices, dressing materials, antibiotics) and indirect costs (lost working days, family involvement, transportation, etc.). For all these reasons, we have decided to evaluate treatment of traumatic lesions of the limbs with an advanced wound care dressing which proposes to promote and sustain effective coverage of bony and tendon structures and, simultaneously, to accelerate the healing process through an induction of the dermal component.

A previous clinical study with a product based on Hyaluronic acid was carried out on deep partial and fullthickness burns in young and adult patients [13]. In contrast, we have utilized this dermal substitute in severe extremity injuries, although less life-threatening than burns but still present as a difficult soft tissue problem for limb salvage. These results suggest the product does induce the production of new granulation tissue suitable for receiving a new epithelial cover.

The effective protection provided by the layer of silicon from infections was supported by the incidence of 1 case with infection $(6.7 \%)$ in this series. The outer silicone membrane barrier may limit colonization and therefore protect the hyaluronan from protease digestion.
Table 2 Efficacy and safety results
${ }^{\text {a }}$ Evaluation of inflammatory indexes (white cells, C-RP and ESR) were carried out at 3,6 , 10 days and 4 weeks after the application of Hyalomatrix ${ }^{\circledR} \mathrm{PA}$

${ }^{b}$ Evaluation at least 6 weeks after Hyalomatrix ${ }^{\circledR}$ PA application (skin texture, skin color similarity and elasticity)

\begin{tabular}{llllll}
\hline $\mathrm{N}^{\circ}$ & $\begin{array}{l}\text { Inflammatory } \\
\text { indexes }^{\mathrm{a}}\end{array}$ & $\begin{array}{l}\text { Skin } \\
\text { autograft }\end{array}$ & $\begin{array}{l}\text { Time to } \\
\text { complete } \\
\text { healing } \\
\text { (days) }\end{array}$ & $\begin{array}{l}\text { Quality } \\
\text { of the } \\
\text { skin }^{\mathrm{b}}\end{array}$ & Complications \\
\hline 1 & Negative & Yes & 28 & Moderate & - \\
2 & Positive & No & 30 & Good & - \\
3 & Positive & No & 21 & Optimal & - \\
4 & Positive & Yes & 21 & Good & - \\
5 & Positive & Yes & 28 & Optimal & - \\
6 & Positive & No & 23 & Good & - \\
7 & Positive & No & 21 & Optimal & - \\
8 & Positive & No & 16 & Optimal & - \\
9 & Positive & No & 30 & Normal & - \\
10 & Positive & No & 28 & Good & - \\
11 & Positive & No & 16 & Moderate & - \\
12 & Negative & Yes & 60 & Moderate & Infection \\
13 & Positive & Yes & 28 & Good & - \\
14 & Positive & No & 30 & Good & - \\
15 & Positive & No & 23 & Good & - \\
\hline
\end{tabular}


Fig. 1 Patient with traumatic injury of the right hand. a Lesion after surgical debridement, $\mathbf{b}$ application of Hyalomatrix ${ }^{\circledR}$ PA, c lesion after the Hyalomatrix ${ }^{\circledR}$ removal, d lesion completed healed (after 30 days)
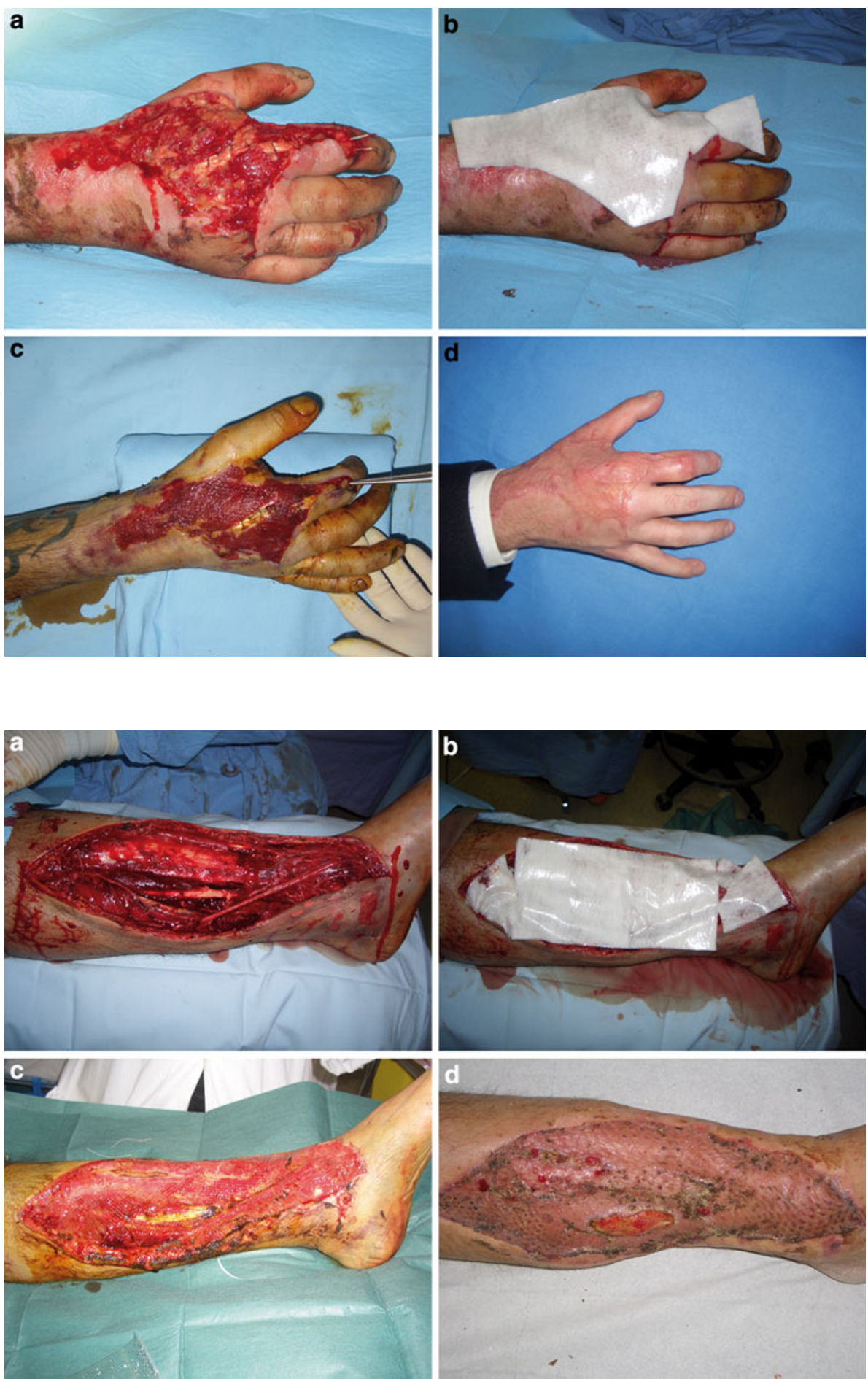

Fig. 2 Patient with a lower limb traumatic lesion. a Lesion after surgical debridement, b application of Hyalomatrix ${ }^{\circledR}$ PA, c lesion after Hyalomatrix ${ }^{\circledR}$ PA removal: the newly formed tissue is evident, $\mathbf{d}$ after one month: $>90 \%$ taking of the meshed-skin graft
During this study, despite the transparent nature of the external silicon layer, we were not able to verify specific changes on the wound bed until removal of the product around the fourteenth day of treatment. This observational study has confirmed some remarkable induction capabilities of this dermal substitute on producing granulation tissue suitable for split skin grafts. Although pain relief was demonstrated for the intra-articular introduction of hyaluronic acid derivatives in the treatment of osteoarthritis [14, 15], we have not measured this clinical effect in the patients in this study. Myers et al. [16-19] have proposed a role of HA in the induction of angiogenesis in granulation tissue. In a previous clinical study, Price et al. $[20,21]$ have suggested that Hyalomatrix ${ }^{\circledR}$ might function as a dermal regenerative template because of its high level of esterification in $\mathrm{HYAFF}^{\circledR}$, and this is supported by the 
observation of early wound epithelialization. This study has shown satisfactory results with this approach, but it stressed the importance that close monitoring of wound progress is made. For these reasons, we believe that a hyaluronic acid-derived dermal substitute can be indicated for non-invasive treatment of complicated traumatic wounds where there is need for a dermal inductive effect to cover important structures and a need of protection from infections [13]. The quality of the neo-dermal tissue is clinically better than dystrophic scar tissue that would be obtained from healing by secondary intention, but it is not yet comparable to that of the original healthy skin. On certain locations such as hands, knees, elbows and ankles, use of this substitute will need longer-term follow-up for the possible onset of contractures which could affect function. Finally, with this approach to wound cover, there is need for high patient compliance and specific physiotherapy aimed at functional recovery after the immobilization of the treated area.

\section{Conclusion}

This study has evaluated the performance of a dermal substitute for the cover of wounds to limbs after trauma. Successful cover was achieved in all cases, with the need of additional split thickness skin grafts in $33 \%$ of patients. Infection was encountered in one patient.

Conflict of interest The authors declare that they have no conflict of interest.

Open Access This article is distributed under the terms of the Creative Commons Attribution License which permits any use, distribution, and reproduction in any medium, provided the original author(s) and the source are credited.

\section{References}

1. Gravante G, Sorge R, Merone A, Tamisani AM, Di Lonardo A, Scalise A, Doneddu G, Melandri D, Stracuzzi G, Onesti MG, Cerulli P, Pinn R, Esposito G (2010) Hyalomatrix PA in burn care practice: results from a national retrospective survey, 2005 to 2006. Ann Plast Surg 64(1):69-79

2. Volpi N, Schiller J, Stern R, Soltés L (2009) Role, metabolism, chemical modifications and applications of Hyaluronan. Curr Med Chem 16(14):1718-1745

3. Balazs EA, Laurent TC, Jeanloz RW (1986) Nomenclature of hyaluronic acid. Biochem J. 235:903
4. Foschi D, Castoldi L, Radaelli E, Abelli P, Calderini G, Rastrelli A, Mariscotti C, Marazzi M, Trabucchi E (1990) Hyaluronic acid prevents oxygen free-radical damage to granulation tissue: a study in rats. Int J Tissue React 12:333

5. Weigel PH, Frost SJ, McGary CT, LeBoeuf RD (1988) The role of hyaluronic acid in inflammation and wound healing. Int $\mathrm{J}$ Tissue React 10:355

6. King SR, Hickerson WL, Proctor KG (1991) Beneficial actions of exogenous hyaluronic acid on wound healing. Surgery 109:76

7. Voinchet V, Vasseur P, Kern J (2006) Efficacy and safety of hyaluronic acid in the management of acute wounds. Am J Clin Dermatol 7:353

8. Campoccia D, Doherty P, Radice M, Brun P, Abatangelo G, Williams DF (1998) Semisynthetic resorbable materials from hyaluronan esterification. Biomaterials 19:2101

9. West DC, Hampson IN, Arnold F, Kumar S (1985) Angiogenesis induced by degradation products of hyaluronic acid. Science 228:1324

10. Rooney P, Kumar S (1993) Inverse relationship between hyaluronan and collagens in development and angiogenesis. Differentiation 54:1

11. Barbucci R, Magnani A, Baszkin A, Da Costa ML, Bauser H, Hellwig G, Martuscelli E, Cimmino S (1993) Physico-chemical surface characterisation of hyaluronic acid derivatives as a new class of biomaterials. J Biomater Sci Polym Ed 4:245

12. Gravante G, Delogu D, Giordan N, Morano G, Montone A, Esposito G (2007) The use of Hyalomatrix PA in the treatment of deep partial-thickness burns. J Burn Care Res. 28(2):269-274

13. Perrot $P$, Dellière V, Brancati A, Duteille F (2011) Hyalomatrix PA $\left({ }^{\circledR}\right)$ in skin substitutes. About 10 cases. Ann Chir Plast Esthet 56(2):107-111. doi:10.1016/j.anplas.2010.10.006

14. Iannitti T, Lodi D, Palmieri B (2011) Intra-articular injections for the treatment of osteoarthritis: focus on the clinical use of hyaluronic acid. Drugs R D 11(1):13-27

15. Eyigör C, Pirim A, Eyigör S, Uyar M (2010) Efficacy of intraarticular hyaluronic acid injection through a lateral approach under fluoroscopic control for advanced hip osteoarthritis. Agri. 22(4):139-144

16. Myers SR, Partha VN, Soranzo C, Price RD, Navsaria HA (2007) Hyalomatrix: a temporary epidermal barrier, hyaluronan delivery, and neodermis induction system for keratinocyte stem cell therapy. Tissue Eng 13(11):2733-2741. doi:10.1089/ten.2007.0109

17. West DC, Hampson IN, Arnold F, Kumar S (1991) Angiogenesis induced by degradation products of hyaluronic acid. Science 228:1324

18. Kangesu T, Manek S, Terenghi G, Gu XH, Navsaria HA, Polak JM, Green CJ, Leigh IM (1998) Nerve and blood vessel growth in response to grafted dermis and cultured keratinocytes. Plast Reconstr Surg 101:1029

19. Jaworski DM, Kelly GM, Hockfield S (1995) The CNS specific hyaluronan-binding protein $\mathrm{BEHAB}$ is expressed in ventricular zones coincident with gliogenesis. J Neurosci 15:1352

20. Price RD, Das-Gupta V, Leigh IM, Navsaria HA (2006) A comparison of tissue-engineered hyaluronic acid dermal matrices in a human wound model. Tissue Eng 12(10):2985-2995

21. Harris PA, di Francesco F, Barisoni D, Leigh IM, Navsaria HA (1999) Use of hyaluronic acid and cultured autologous keratinocytes and fibroblasts in extensive burns [letter]. Lancet 353:35 